\title{
NEOINTIMAL FORMATION AT THE SITES OF ANASTOMOSIS OF THE INTERNAL THORACIC ARTERY GRAFTS AFTER CORONARY ARTERY BYPASS GRAFTING IN HUMAN SUBJECTS: AN IMMUNOHISTOCHEMICAL ANALYSIS
}

Mitsuharu Hosono, MD

Makiko Ueda, $\mathrm{MD}^{\mathrm{b}}$

Shigefumi Suehiro, $\mathrm{MD}^{\mathrm{a}}$

Yasuyuki Sasaki, MD

Toshihiko Shibata, MD $^{\mathrm{a}}$

Koji Hattori, MD

Hiroaki Kinoshita, MD
Objectives: The aim of this study was to evaluate the cellular composition and cell proliferative activity of neointimal tissue in human internal thoracic artery grafts and to characterize the differentiation state of neointimal smooth muscle cells at early stages after coronary artery bypass grafting.

Methods: The anastomotic sites and body segments of 7 patent grafts were obtained at autopsy from 7 patients who died within 92 days after operation. Serial sections were examined by immunohistochemical techniques to identify macrophages, endothelial cells, smooth muscle cell phenotype, and proliferating cells. For the identification of the cell types that show cell proliferative activity, immunodouble staining was also performed.

Results: In all body segments the luminal surface was completely covered by endothelial cells, and no areas showed thrombus formation or neointimal proliferation after grafting. In contrast, in the anastomotic segments endothelial denudation and focal disruption of the internal elastic lamina with adherence of fibrin-platelet thrombus and infiltration of macrophages were observed in the earliest stage after grafting. At these sites of injury, early neointimal tissue response had occurred, and cell proliferative activity was detected in macrophages and dedifferentiated smooth muscle cells. During the evolution of neointimal thickening, redifferentiation of neointimal smooth muscle cells occurred associated with the decline in proliferative activity.

Conclusions: These observations strongly support the concept that excessive neointimal proliferation, which may occur at the site of anastomosis because of extensive damage to the arterial wall, could be one of the possible causes of failure of the internal thoracic artery graft in human beings. ( $\mathrm{J}$ Thorac Cardiovasc Surg 2000;120:319-28)
$T^{\prime}$ he internal thoracic artery (ITA) as a conduit for coronary artery bypass grafting (CABG) has proved to be superior to the saphenous vein graft. ${ }^{1-3}$ Although the majority of ITA grafts achieve long-term patency, there is still the occasional patient who shows stenosis or occlu-

From the Second Department of Surgery a and the Department of Pathology, ${ }^{\mathrm{b}}$ Osaka City University Medical School, Osaka, Japan.

Received for publication Sept 30, 1999; revisions requested Dec 23, 1999; revisions received Feb 2, 2000; accepted for publication Feb 7, 2000.

Address for reprints: Makiko Ueda, MD, Department of Pathology, Osaka City University Medical School, 1-4-3, Asahi-machi, Abeno-ku, Osaka 545-8585, Japan.

Copyright (C) 2000 by The American Association for Thoracic Surgery

0022-5223/2000 $\$ 12.00+0 \quad \mathbf{1 2 / 1 / 1 0 6 3 2 8}$

doi: $10.1067 / \mathrm{mtc} .2000 .106328$ sion of the ITA graft. ${ }^{4,5}$ Previous clinical studies have revealed that ITA stenosis commonly occurs at the site of anastomosis ${ }^{4-8}$ and generally develops within 3 months after the operation. ${ }^{8}$ Shimshak and colleagues ${ }^{6}$ suggested that on the basis of angiographic appearance and the interval from surgery, intimal hyperplasia appears to be responsible for anastomotic stenosis in ITA grafts. To the best of our knowledge, however, no systematic studies have focused on histologic and immunohistochemical characteristics of the anastomotic sites of ITA grafts at early stages after CABG in human subjects. The present study examined these characteristics.

\section{Material and methods}

Materials. This study is based on 7 ITA grafts obtained at autopsy from 7 patients who had undergone CABG with an in situ ITA graft but who died within 92 days after the operation. 
Table I. Relevant clinical data

\begin{tabular}{ccccccll}
\hline $\begin{array}{c}\text { Case } \\
\text { No. }\end{array}$ & $\begin{array}{c}\text { Age } \\
(y)\end{array}$ & Sex & $\begin{array}{c}\text { Reason for } \\
\text { CABG }\end{array}$ & $\begin{array}{c}\text { Site of } \\
\text { anastomosis }\end{array}$ & $\begin{array}{c}\text { Interval } \\
\text { CABG-death }\end{array}$ & $\begin{array}{c}\text { Cause of } \\
\text { death }\end{array}$ & \multicolumn{1}{c}{ Coronary risk factors } \\
\hline 1 & 68 & F & AMI & LAD & $8 \mathrm{~h}$ & Cardiac failure & Hypercholesterolemia \\
2 & 74 & F & UAP & LAD & $2 \mathrm{~d}$ & Rupture of AAA & Hypercholesterolemia \\
3 & 64 & M & UAP & LAD & $7 \mathrm{~d}$ & Mediastinitis & Smoking \\
4 & 72 & M & UAP & LAD & $19 \mathrm{~d}$ & Cardiac failure & Smoking \\
5 & 61 & M & AMI & LAD & $23 \mathrm{~d}$ & Pneumonia & Gout, smoking \\
6 & 56 & M & UAP & LAD & $56 \mathrm{~d}$ & Cardiac failure & Diabetes mellitus, gout \\
7 & 73 & M & AMI & LAD & $92 \mathrm{~d}$ & Renal failure & Hypercholesterolemia, diabetes mellitus, smoking \\
\hline
\end{tabular}

$A M I$, Acute myocardial infarction; $L A D$, left anterior descending artery; $U A P$, unstable angina pectoris; $A A A$, abdominal aortic aneurysm.

Table II. Monoclonal antibodies used in the study

\begin{tabular}{|c|c|c|c|c|}
\hline Antibody & Specificity and reactivity & Reference & Source & $\begin{array}{c}\text { Working } \\
\text { in dilution }\end{array}$ \\
\hline HHF-35 & Muscle actin & Gown et $\mathrm{al}^{9}$; Tsukada et a ${ }^{10}$ & Dako & $1: 50$ \\
\hline CGA-7 & Smooth muscle cell actin & Gown et $\mathrm{al}^{9}$; Gown et $\mathrm{al}^{11}$ & Enzo & $1: 20$ \\
\hline Anti-vimentin & Smooth muscle cells, fibroblasts, macrophages, endothelial cells & & Dako & $1: 70$ \\
\hline HAM-56 & Macrophages, some endothelial cells & Gown et $\mathrm{al}^{9}$ & Dako & $1: 70$ \\
\hline PGM-1 & Macrophages & & Dako & $1: 100$ \\
\hline Anti-vWf & Endothelial cells & & Dako & 1:50 \\
\hline Anti-PCNA & Proliferating cells & & Dako & $1: 50$ \\
\hline
\end{tabular}

Antibodies were obtained from Dako A/S (Glostrup, Denmark) and Enzo Biochemicals, Inc (New York, NY).

All ITA grafts were patent. Table I gives the relevant clinical data. The interval between CABG and death ranged from 8 hours to 92 days. The causes of death of these patients were cardiac failure, rupture of abdominal aortic aneurysm, mediastinitis, pneumonia, and renal failure. In patient 3 the mediastinitis did not involve the ITA area. All ITA-coronary artery anastomoses were constructed in an end-to-side fashion with continuous 8-0 monofilament sutures.

Fifteen nonimplanted ITA segments, harvested at surgery, were also studied as controls.

Methods. The post-CABG heart specimens and normal ITA segments were fixed in methanol-Carnoy fixative $(60 \%$ methanol, $30 \%$ chloroform, and $10 \%$ glacial acetic acid). This method of fixation has the advantage that the immunohistochemical investigations necessary for this study can be performed on paraffin-embedded sections.

The ITA grafts, together with the left anterior descending arteries, which contained the sites of anastomosis, were removed from the epicardial surface. The anastomotic sites were cut serially at $2-\mathrm{mm}$ intervals perpendicular to the long axis, and two slices from each anastomotic site were obtained (slices from anastomotic sites, $\mathrm{n}=14$ ). The bodies of the grafts were also cut serially at 5-mm intervals, and 10 slices from each body segment were obtained (slices from body segments, $n=70$ ). Then a total number of 84 slices from both anastomotic and body segments of the ITA grafts were examined.

All slices obtained from the ITA grafts and from control segments were processed routinely and embedded in paraffin.
From each slice, 20 serial sections were cut at a thickness of $5 \mu \mathrm{m}$. Every first and second section was stained with conventional hematoxylin-eosin and Weigert elastic-van Gieson stain, respectively. The other sections were used for immunohistochemical staining.

Immunohistochemistry. The primary monoclonal antibodies used for the identification of smooth muscle cells (SMCs) were the anti-SMC actin markers HHF-35 and CGA7. For endothelial cell identification, an anti-von Willebrand factor (vWf) antibody was used. HAM-56 and PGM-1 were used for the identification of macrophages. An anti-vimentin monoclonal antibody was used to identify mesenchymal cells. A monoclonal antibody to proliferating cell nuclear antigen (PCNA) was used to detect proliferating cells. The source, specification, and working dilution of the antibodies used are summarized in Table II. ${ }^{9-11}$

Single staining. Sections were incubated with the primary antibodies for 1 hour at room temperature. The labeled streptavidin-biotin complex system with nickel chloride color modification was performed in all instances. Sections were counterstained with methyl green.

Evaluation of phenotypic differentiation of SMCs. In this study the differentiation state of SMCs was evaluated by use of two anti-actin markers, HHF-35 and CGA-7, according to our previous studies. ${ }^{12-14}$ Highly differentiated SMCs stain positive with both HHF-35 and CGA-7, whereas dedifferentiated SMCs stain negative with both HHF-35 and CGA-7, and intermediately differentiated SMCs stain positive with HHF-35 but negative with CGA-7. 


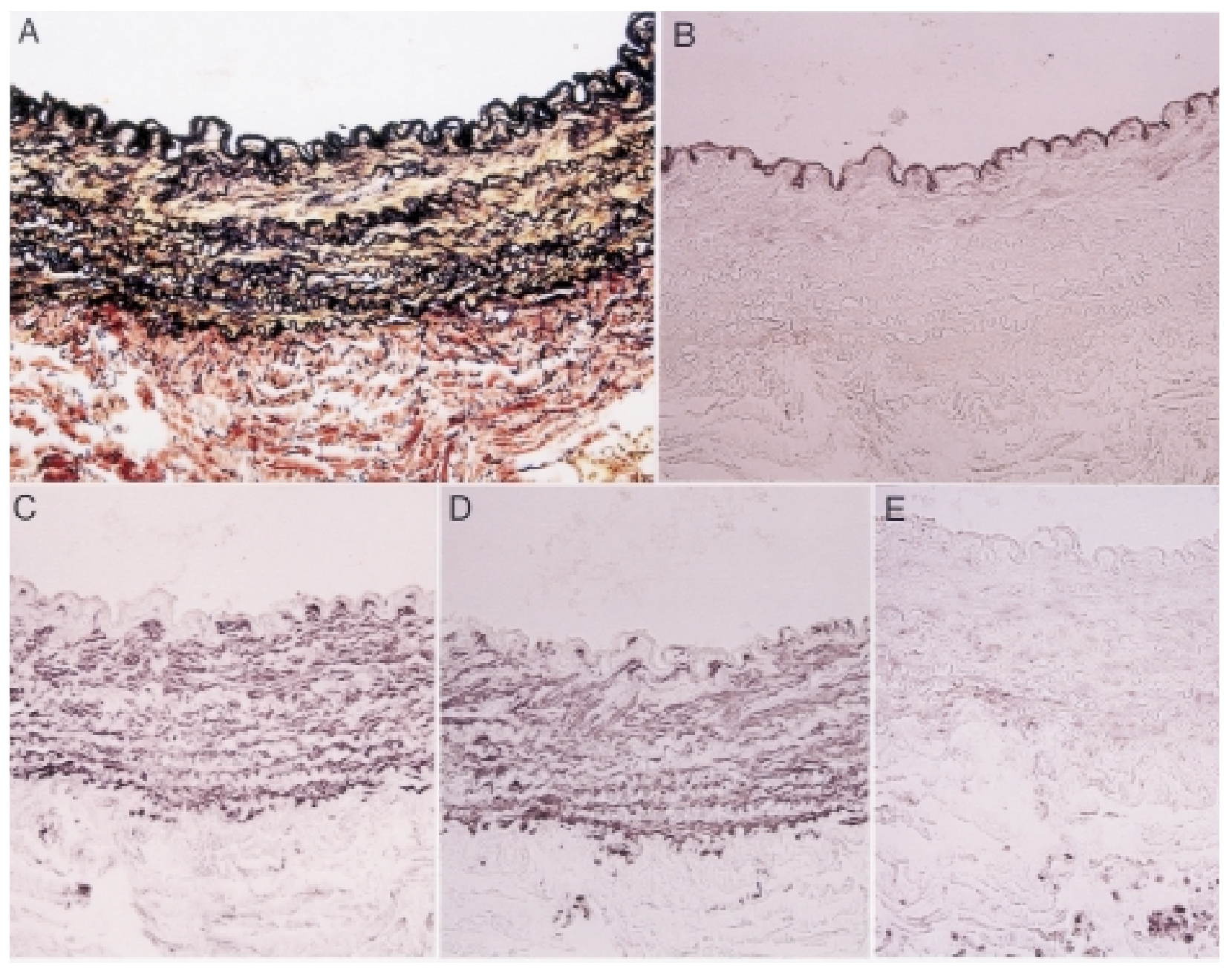

Fig 1. Micrographs of a body segment 2 days after grafting. Panels A-E represent serial sections. A, Elastic tissue stain. No injuries are seen in the arterial wall. B, Staining with anti-vWf. The luminal surface is completely covered by vWf-positive endothelial cells. C, Staining with HHF-35. SMCs in the media are positive with HHF-35. D, Staining with CGA-7. SMCs in the media are also positive with CGA-7, indicating that these SMCs are highly differentiated. E, Staining with HAM-56. Scattered macrophages are found in the adventitia, but no macrophages are present in the media. (Original magnification $64 \times$.)

Immunodouble staining. For the simultaneous identification of SMCs and macrophages, sections were double-stained with HHF-35 and HAM-56, according to procedures previously reported. ${ }^{15}$ In this immunodouble staining, we visualized the enzymatic activity of $\beta$-galactosidase for HHF-35 in turquoise (BioGenex Kit, San Ramon) and the activity of alkaline phosphatase for HAM-56 in red (New Fuchsin Kit, Dako).

To evaluate the differentiation state of SMCs in relation to PCNA positivity, we also performed immunodouble staining for SMC actin (HHF-35) and PCNA. In this staining, alkaline phosphatase was visualized with fast blue BB (blue, HHF-35) and peroxidase with 3-amino-9-ethylcarbazole development (red, PCNA).

\section{Results}

Normal ITA segments. Six of the 15 normal ITA segments showed low-grade pre-existent intima with abundant elastic fibers, but none revealed atherosclerotic changes.

Immunohistochemically, the pre-existent intima of these normal ITA specimens contained abundant SMCs, and these intimal SMCs stained positive with both actin markers, HHF-35 and CGA-7, indicating that the intimal SMCs were highly differentiated. The media also consisted of highly differentiated SMCs. Some macrophages were scattered in the adventitia, but no macrophages were found in the media or pre-exis- 


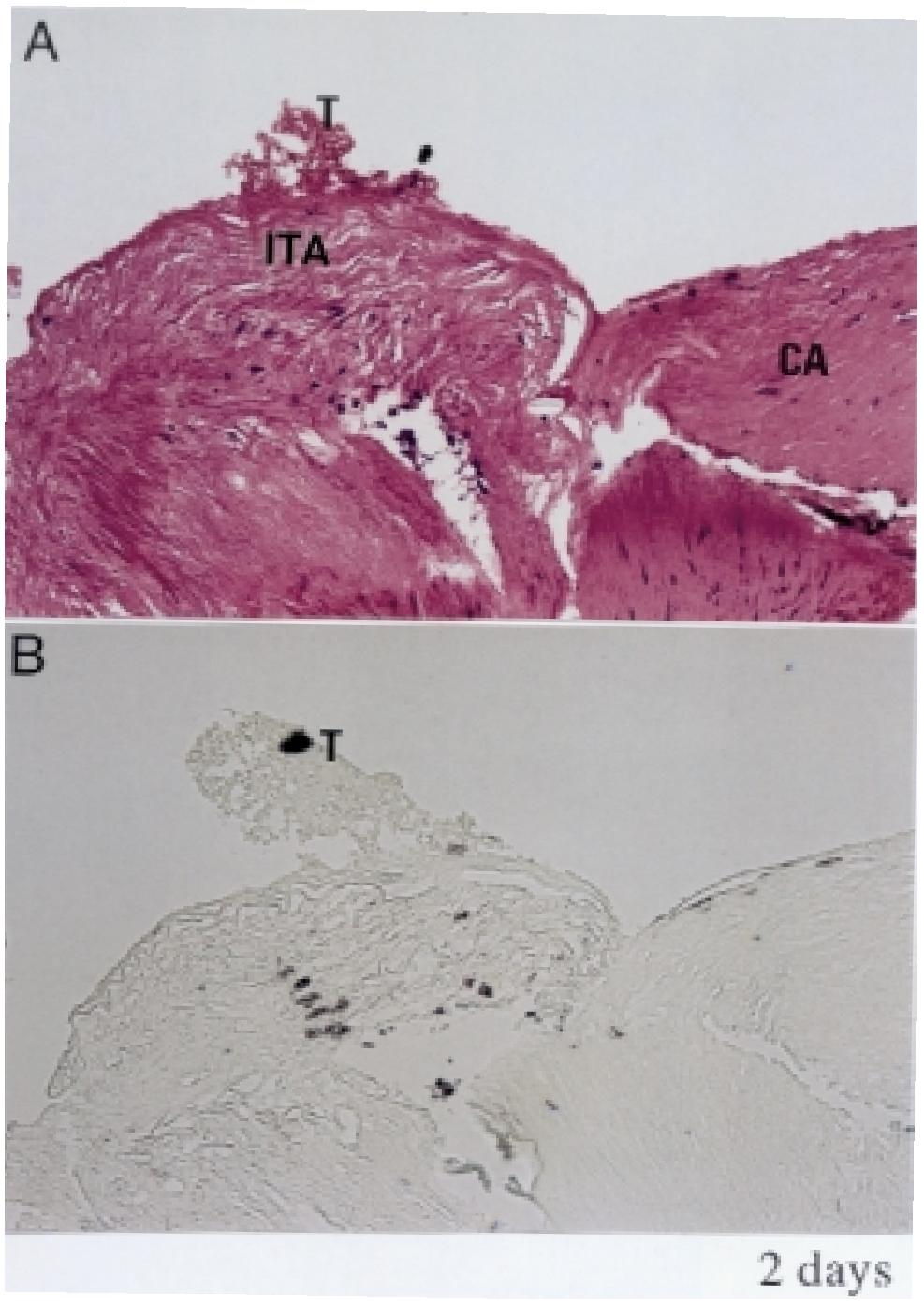

Fig 2. Micrographs of an anastomotic site 2 days after grafting. Panels $\mathbf{A}$ and $\mathbf{B}$ are serial sections. A, Hematoxylin-eosin stain. Adherence of fibrin-platelet thrombus $(T)$ is seen at the site of endothelial denudation and focal disruption of the internal elastic lamina of an ITA. $C A$, Coronary artery. B, Staining with HAM-56. Distinct infiltration of macrophages is present at the site of anastomotic injury. T, Fibrin-platelet thrombus. (Original magnification $86 \times$.)

tent intima. There were no PCNA-positive cells in the normal ITA segment.

ITA grafts after CABG at the body segments. Immunohistochemical studies demonstrated that in all body segments examined the luminal surface was completely covered by vWf-positive endothelial cells (Fig $1, A$ and $B)$. SMCs within the media revealed characteristic features of a highly differentiated state (Fig 1, C and $D$ ), and no or only occasional macrophages were present in the media (Fig 1,E). In these body segments no areas showed formation of fibrin-platelet thrombus or neointimal proliferation after CABG, and no PCNApositive cells were observed.
ITA grafts after CABG at the sites of anastomosis. All slices obtained from anastomotic sites revealed CABG-related pathologic changes. At similar time intervals, the CABG-related pathologic changes observed were remarkably similar. This thus allowed a collective description of the findings for each stage after CABG.

Injury and cellular response. At the earliest stage, less than 2 days after CABG (patients 1 and 2), the histopathologic and immunohistochemical features of the ITA grafts at the sites of anastomosis were characterized by endothelial denudation and focal disruptions of the internal elastic lamina with fibrin-platelet thrombus and infiltration of macrophages (Fig 2). 

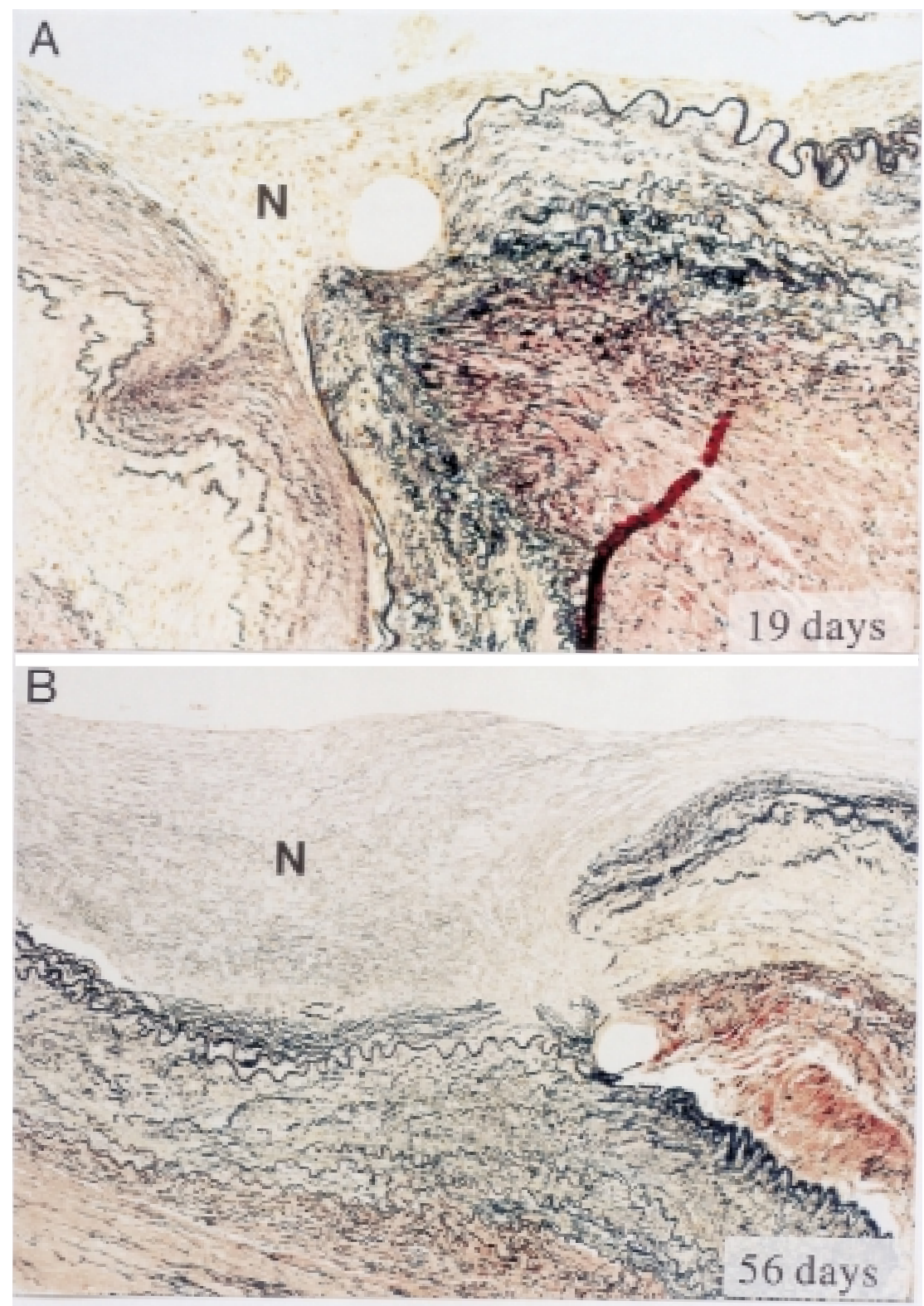

Fig 3. Micrographs showing neointimal tissue formation at the anastomotic sites at different time intervals after grafting. Elastic tissue stain. A, At 19 days, early neointimal tissue $(N)$ is seen. B, At 56 days, a more prominent neointima $(N)$ is found. (Original magnification $129 \times$.)

From 7 days onward (patients 3, 4, 5, 6, and 7), the anastomotic sites showed a distinct layer of neointimal tissue, albeit to varying degrees (Fig 3). Immunodouble staining for macrophages and SMCs revealed that at earlier stages (7, 19, and 23 days after $\mathrm{CABG})$ the neointima was accompanied by distinct accumulation of macrophages (Fig 4, $A$ and $B$ ), whereas at later stages (56 and 92 days after $\mathrm{CABG}$ ) no or only occasional macrophages were identified within the neointima (Fig 4, $C$ and $D$ ).
Cell proliferation at the site of injury. At the earliest stage after CABG, occasional PCNA-positive cells were found in the media. From 7 to 23 days after CABG, PCNA positivity was detected in both the media and neointimal tissue. Immunodouble staining for PCNA and SMC actin (HHF-35) revealed that PCNA-positive cells in these neointimal tissues were actin (HHF-35) negative dedifferentiated SMCs and macrophages (Fig 5, $A$ and $B$ ). 


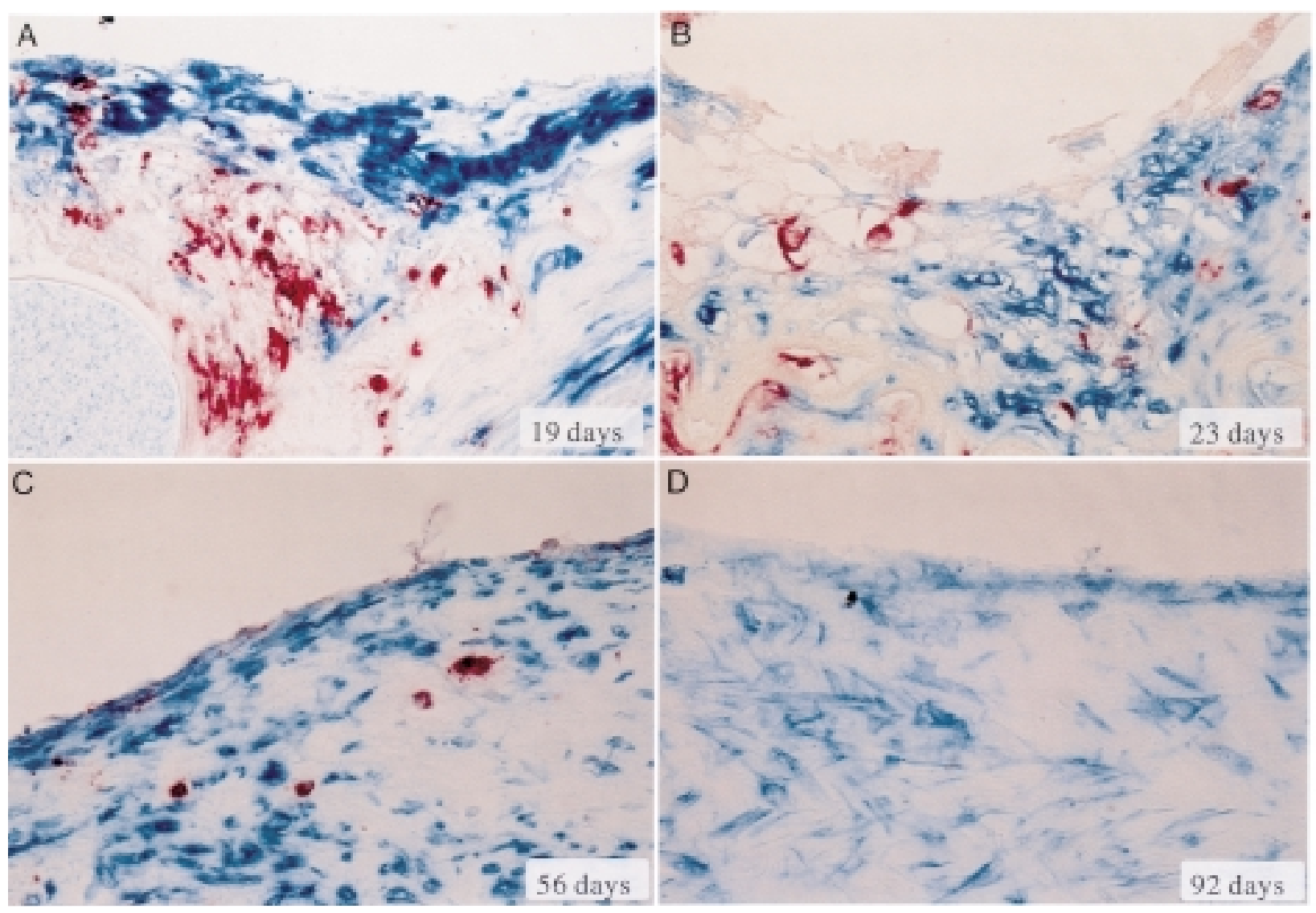

Fig 4. Micrographs showing the cellular composition of neointimal tissue at different time intervals after grafting. Immunodouble staining for macrophages (red) and SMCs (turquoise). A, At 19 days, neointimal tissue is composed of macrophages (red) and SMCs (turquoise). B, At 23 days, abundant macrophages (red) are present in the neointima. C, At 56 days, neointimal tissue is composed mainly of SMCs (turquoise) with only occasional macrophages (red). D, At 92 days, neointimal tissue consists almost entirely of SMCs (turquoise). (Original magnification 404×.)

PCNA positivity within the neointima diminished with time, and from 56 days onward, no PCNA-positive cells were observed (Fig 5, $C$ and $D$ ).

Differentiation states of SMCs within the neointima. At 7 days, the neointimal tissue was composed of macrophages and spindle-shaped cells. Immunohistochemically, the majority of the spindle-shaped cells in the neointima were vimentin positive, HHF-35 negative, and CGA-7 negative, indicating that these spindleshaped cells were dedifferentiated SMCs.

At stages 19 days and 23 days after CABG, most spindle-shaped cells in the neointima became positive with HHF-35 and showed immunohistochemical characteristics of intermediately differentiated SMCs.

From 56 days onward, almost all spindle-shaped cells within the neointima stained positive with both HHF35 and CGA-7, indicating that these cells were highly differentiated SMCs (Fig 6).
Endothelial cell recovery. From 7 to 23 days, no vWf-positive endothelial cells covering the neointimal tissue were found. However, from 56 days onward, a regenerated endothelial layer was observed at the luminal surface of the neointima.

\section{Discussion}

Previous studies have reported that ITA graft stenosis tends to occur early after operation, particularly at the sites of anastomosis. ${ }^{4-8}$ However, the pathologic changes at the sites of anastomosis of the ITA grafts after CABG have been little studied. To the best of our knowledge, this is the first study to demonstrate biologic processes of neointimal tissue proliferation by immunohistochemical techniques in human ITA grafts at sites of anastomosis at early stages and up to 92 days after CABG.

The present study revealed that in human ITA grafts at the earliest stage after CABG, endothelial denudation 


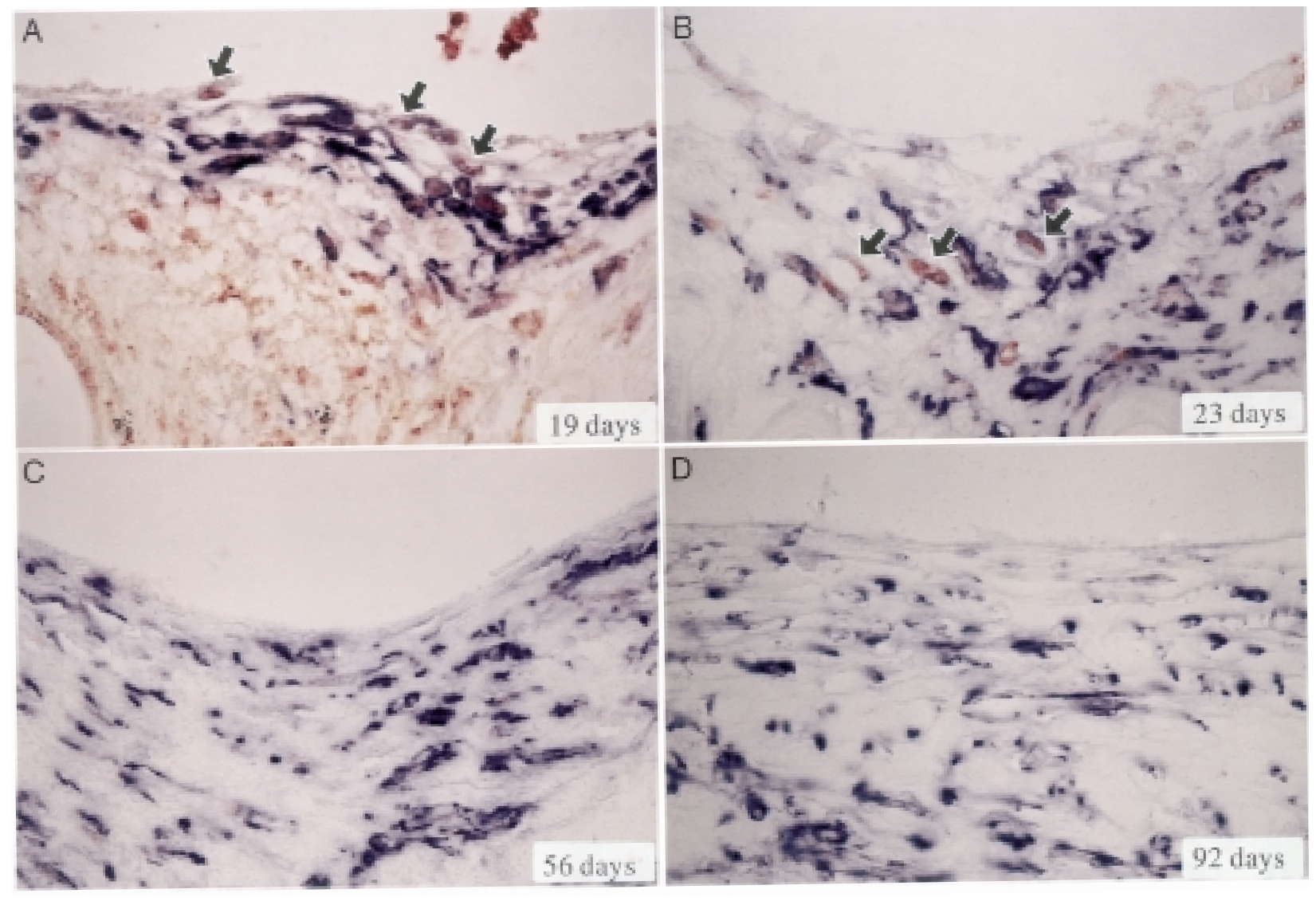

Fig 5. Micrographs showing cell proliferative activity of neointimal tissue at different time intervals after grafting. Immunodouble staining for PCNA (red) and SMC actin (blue). A, At 19 days, both actin-negative dedifferentiated SMCs (arrows) and macrophages in the neointima show PCNA positivity (compared with Fig 4, A). B, At 23 days, PCNA positivity is found in dedifferentiated SMCs (arrows) and macrophages in the neointima (compared with Fig 4, B). C, At 56 days, there are no PCNA-positive cells in the neointima. D, At 92 days, no PCNA-positive cells are seen in the neointima. (Original magnification 539×.)

with adherence of fibrin-platelet thrombus and focal disruption of the internal elastic lamina were found only in the anastomotic segments and not in the body segments. Moreover, immunohistochemical investigations clearly showed that the endothelial cell lining in the body segments was well retained after CABG. At later stages, neointimal tissue response was limited to the injured areas of the anastomotic sites, but no neointimal thickening was found in any segments of the body. In previous postmortem histologic studies, body segments of the ITA grafts after CABG showed no or only mild neointimal thickening. ${ }^{16,17}$ Our findings for the body segments are consistent with these previous reports. Moreover, the present study, with immunohistochemical techniques, provides further support for the hypothesis that retention of endothelial cell lining in the body segments is a major contributing factor to excellent long-term patency rates for ITA grafts after CABG.
It is widely believed that the construction of anastomosis causes focal damage to the arterial wall, which is subsequently repaired by neointimal tissue response; this concept is inferred largely from findings in experimental animals. ${ }^{18-23}$ To date, in human ITA grafts detailed characterization of anastomotic neointimal thickening is lacking. The present immunohistochemical study provides new findings on the nature of the cellular mechanisms that underlie neointimal thickening at the sites of anastomosis in human ITA grafts. This study revealed endothelial denudation with deposition of fibrin-platelet thrombus and infiltration of macrophages at the anastomotic sites at the earliest stage examined less than 2 days after CABG. Our immunohistochemical investigation, using immunodouble staining techniques with SMCs and macrophages, also found that at subsequent stages (7-23 days after $\mathrm{CABG}$ ) macrophage infiltration within the 

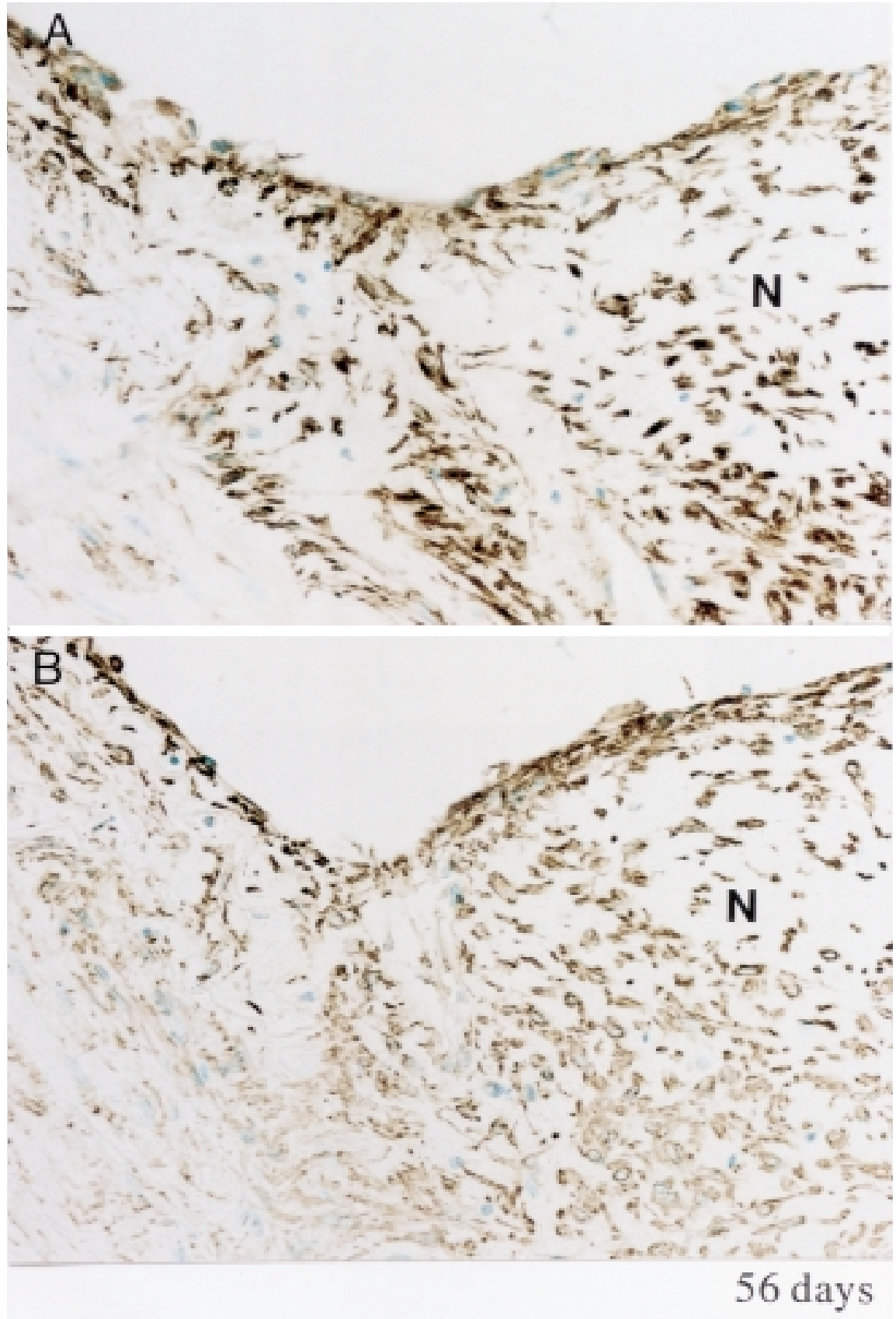

Fig 6. Micrographs showing redifferentiation of SMCs within the neointima 56 days after grafting. A, Staining with HHF-35. Almost all spindle-shaped cells within the neointima $(N)$ are positive with HHF-35. B, Staining with CGA-7. These cells in the neointima $(N)$ also stain positive with CGA-7, indicating that these cells are highly differentiated SMCs. (Original magnification $322 \times$.)

neointima occurred transiently. These data strongly suggest that the initial endothelial denudation with adherence of fibrin-platelet thrombus and the infiltration of macrophages are key events in the early stage of neointimal proliferation. Recent in vitro studies have suggested that platelet thrombus and macrophages secrete a variety of cytokines and growth factors that are important in SMC proliferation and chemotaxis. ${ }^{24,25}$ These experimental data and our present findings support the hypothesis that release of such fac- 
tors from platelets and macrophages promotes SMC proliferation and migration in the process of neointimal formation at the anastomotic site of the ITA graft after CABG in human subjects.

Previous experimental work in animal models after vascular injury has shown that redifferentiation of SMCs occurs during the evolution of neointimal thickening, as revealed by changes in the expression of cytoskeletal proteins. ${ }^{13,26,27}$ Our previous studies in human coronary arteries after percutaneous transluminal coronary angioplasty also demonstrated a similar shift in the cytoskeletal phenotype of neointimal SMCs. ${ }^{12,28}$ The present study, for the first time, provides evidence that redifferentiation of SMCs occurs as part of the evolution of neointimal thickening at the anastomotic sites in human ITA grafts.

This study also provides new data with regard to cell proliferative activity related to anastomotic injury in human ITA grafts. At early stages after CABG, cell proliferative activity was identified in both the media and neointima at the sites of anastomosis. In the latter, both macrophages and dedifferentiated SMCs showed cell proliferation. However, at later stages from 56 days onward, proliferative activity could no longer be detected within the neointima; at these stages, the neointima consisted predominantly of highly differentiated SMCs. These observations suggest that the decline in cell proliferative activity during the evolution of the neointima is related to the redifferentiation of neointimal SMCs. This concept is supported by previous experimental studies of neointimal cellular kinetics and phenotypic changes of SMCs. ${ }^{13,26,27}$ In human subjects, however, there is only scant evidence of cell proliferation as part of the process of neointimal formation. O'Brien and colleagues, ${ }^{29}$ using an antibody against PCNA to examine cell proliferation in atherectomy specimens obtained from human coronary restenotic lesions after angioplasty, found that cell proliferation occurred infrequently and at low levels in these specimens. The differences between our observations and those reported by O'Brien and colleagues may be related to differences in tissue characteristics or to differences in time factors. In our study PCNA positivity was found frequently only in the early stages after $\mathrm{CABG}$, and it is unlikely that the restenotic lesions observed by O'Brien and colleagues are similar to our materials. In our materials, moreover, immunodouble staining for PCNA and SMC actin revealed distinct PCNA positivity in dedifferentiated SMCs. These observations strongly suggest that a close relationship between SMC dedifferentiation and enhanced proliferative activity is present in human ITA grafts at the early stages after anastomotic injury.
Clinical implications. Our study documented that endothelial injuries and focal disruption of the internal elastic lamina with adherence of fibrin-platelet thrombus and infiltration of macrophages are the most prominent changes in the earliest stage after CABG of the anastomotic sites of human ITA grafts. These observations strongly suggest that mural thrombosis with macrophage infiltration triggers the healing process, which may eventually lead to anastomotic neointimal thickening. Indeed, platelet adherence and aggregation promote the subsequent healing process through the release of growth factors. $^{22,23}$ Pharmacologic intervention at the very early stage after CABG (eg, suppression of the aggregation of platelets at sites of anastomotic injury by using inhibitors of platelet glycoprotein IIb/IIIa receptor) can therefore be recommended, although this treatment may possibly increase bleeding complications if these substances are given systemically.

Failure of the ITA grafts early after CABG is not frequent, and therefore the nature of early occlusive changes at the site of anastomosis has not been completely defined. Some possible causes have been suggested: technical faults, thrombosis, or intimal hyperplasia. ${ }^{4}$ Our present findings strongly suggest that excessive neointimal proliferation, which may occur at the site of anastomosis as a result of extensive damages to the arterial wall, could be one of the possible causes of failure of the ITA grafts in human subjects.

Study limitations. It is extremely difficult to acquire suitable ITA grafts from autopsied cases for reliable immunohistochemical studies. With respect to the attempt to represent a time-related sequence of events after anastomotic injuries in human ITA grafts after $\mathrm{CABG}$, the main limitation is the small number of autopsied cases studied. Nevertheless, our findings are intriguing because experimental angioplasty injuries and human coronary arteries after angioplasty have shown similar pathologic processes of neointimal thickening.

\section{REFERENCES}

1. Lytle BW, Loop FD, Cosgrove DM, Ratliff NB, Easley K, Taylor PC. Long-term (5 to 12 years) serial studies of internal mammary artery and saphenous vein coronary bypass grafts. J Thorac Cardiovasc Surg 1985;89:248-58.

2. Loop FD, Lytle BW, Cosgrove DM, Stewart RW, Goormastic M, Williams GW, et al. Influence of the internal-mammary artery graft on 10-year survival and other cardiac events. N Engl J Med 1986;314:1-6.

3. Cameron A, Davis KB, Green G, Schaff HV. Coronary bypass surgery with internal-thoracic-artery grafts effects on survival over a 15-year period. N Engl J Med 1996;334:216-9.

4. Grondin CM, Campeau L, Lesperance J, Enjalbert M, Bourassa M. Comparison of late changes in internal mammary artery and saphenous vein grafts in two consecutive series of patients 10 years after operation. Circulation 1984;70(Suppl):I-208-12. 
5. Fitzgibbon GM, Kafka HP, Leach AJ, Keon WJ, Hooper GD, Burton JR. Coronary bypass graft fate and patient outcome: angiographic follow up of 5065 grafts related to survival and reoperation in 1388 patients during 25 years. J Am Coll Cardiol 1996;28:616-26.

6. Shimshak TM, Giorgi LV, Johnson WL, McConahay DR, Rutherford BD, Ligon R, et al. Application of percutaneous transluminal coronary angioplasty to the internal mammary artery graft. J Am Coll Cardiol 1988;12:1205-14.

7. Tector AJ. Fifteen years' experience with the internal mammary artery graft. Ann Thorac Surg 1986;42(Suppl):S22-7.

8. Najm HK, Leddy D, Hendry PJ, Marquis JF, Richardson D, Keon WJ. Postoperative symptomatic internal thoracic artery stenosis and successful treatment with PTCA. Ann Thorac Surg 1995;59:323-7.

9. Gown AM, Tsukada T, Ross R. Human atherosclerosis. II. Immunocytochemical analysis of the cellular composition of human atherosclerotic lesions. Am J Pathol 1986;125:191-207.

10. Tsukada T, McNutt MA, Ross R, Gown AM. HHF-35, a muscleactin-specific monoclonal antibody. II. Reactivity in normal, reactive, and neoplastic human tissues. Am J Pathol 1987;127:389-402.

11. Gown AM, Vogel AM, Gordon D, Lu PL. A smooth muscle-specific monoclonal antibody recognizes smooth muscle actin isozymes. J Cell Biol 1985;100:807-13.

12. Ueda M, Becker AE, Tsukada $T$, Numano $F$, Fujimoto $T$. Fibrocellular tissue response after percutaneous transluminal coronary angioplasty: an immunocytochemical analysis of the cellular composition. Circulation 1991;83:1327-32.

13. Takagi M, Ueda M, Becker AE, Takeuchi K, Takeda T. The Watanabe heritable hyperlipidemic rabbit is a suitable experimental model to study differences in tissue response between intimal and medial injury after balloon angioplasty. Arterioscler Thromb Vasc Biol 1997;17:3611-9.

14. Ohishi M, Ueda M, Rakugi H, Okamura A, Naruko T, Becker AE, et al. Upregulation of angiotensin-converting enzyme during the healing process after injury at the site of percutaneous transluminal coronary angioplasty in humans. Circulation 1997;96:3328-37.

15. van der Loos CM, Becker AE, van den Oord JJ. Practical suggestions for successful immunoenzyme double-staining experiments. Histochem J 1993;25:1-13.

16. Kalan JM, Roberts WC. Comparison of morphologic changes and luminal sizes of saphenous vein and internal mammary artery after simultaneous implantation for coronary artery bypass grafting. Am J Cardiol 1987;60:193-6.
17. van Son JAM, Falk V, Walther T, Smedts FM, Mohr FW. Lowgrade intimal hyperplasia in internal mammary and right gastroepiploic arteries as bypass grafts. Ann Thorac Surg 1997;63:706-8.

18. Tsitsopoulos P, Malbouisson AM, Harrison MJ. End-to-side vascular anastomosis: a study of technical considerations in the rat. J Neurosurg 1982;56:642-5.

19. Aarnio P, Harjula A, Lehtola A, Sariola H, Mattila S. Polydioxanone and polypropylene suture material in free internal mammary artery graft anastomoses. J Thorac Cardiovasc Surg 1988;96:741-5.

20. Bassiouny HS, White S, Glagov S, Choi E, Giddens DP, Zarins CK. Anastomotic intimal hyperplasia: mechanical injury or flow induced. J Vasc Surg 1992;15:708-17.

21. Thomson SR, Gregory MA, Mars M, Natasen J, Naicker T, Baker LW. Morphological aspects of microarterial anastomoses: a comparison of nylon with polydioxanone. Br J Plast Surg 1995;48: 165-71.

22. Brennen MD, O'Brien BM. Patency rates in end to side anastomosis in the rabbit. Br J Plast Surg 1979;32:24-30.

23. Guity A, Young PH, Fischer VW. In search of the "perfect" anastomosis. Microsurgery 1990;11:5-11.

24. Libby P. Schwartz D, Brogi E, Tanaka H, Clinton SK. A cascade model for restenosis. A special case of atherosclerosis progression. Circulation 1992;86(Suppl):III-47-53.

25. Ross R. The pathogenesis of atherosclerosis: perspective for the 1990s. Nature 1993;362:801-9.

26. Kocher O, Gabbiani F, Gabbiani G, Reidy MA, Cokay MS, Peters $\mathrm{H}$, et al. Phenotypic features of smooth muscle cells during the evolution of experimental carotid artery intimal thickening. Lab Invest 1991;65:459-70.

27. Bai H, Matsuda J, Sawa Y, Nakano S, Shirakura R, Shimazaki Y, et al. Neointima formation after vascular stent implantation, spatial and chronological distribution of smooth muscle cell proliferation and phenotypic modulation. Arterioscler Thromb 1994;14:1846-53.

28. Ueda M, Becker AE, Naruko T, Kojima A. Smooth muscle cell de-differentiation is a fundamental change preceding wound healing after percutaneous transluminal coronary angioplasty in humans. Coron Artery Dis 1995;6:71-81.

29. O'Brien ER, Alpers CE, Stewart DK, Ferguson M, Tran N, Gordon D, et al. Proliferation in primary and restenotic coronary atherectomy tissue: implications for antiproliferative therapy. Circ Res 1993;73:223-31. 